\title{
A PSICANÁLISE E AS NARRATIVAS MODERNAS - A TRANSMISSÃO EM QUESTÃO
}

\author{
Anna Carolina Lo Bianco* \\ Fernanda Costa-Moura** \\ Marisa Cytryn Solberg***
}

\section{Resumo}

Em $O$ narrador, Benjamin afirma que a narrativa que transmitia a experiência coletiva é substituída na modernidade pela informação jornalística e pelo romance, cujos objetos são as experiências individuais. Trata-se do momento de emergência da narrativa centrada no eu, ou no que Freud isolou como o "romance familiar do neurótico". Contudo, no romance e no conto prepondera a busca do sentido que possa suportar as vicissitudes de um eu que não encontra amparo na vida compartilhada; já a psicanálise inaugura uma práxis que dará lugar a um sujeito não mais igual ao eu individual. A intervenção analítica realiza, através da fala, uma operação com a história que permite a emergência do sujeito do inconsciente. Ponto de ancoragem de uma transmissão que, embora instaurada no campo das narrativas modernas, não se apoia no sentido e constitui um campo que se realiza apenas no fragmentário e no pontual.

Palavras-chave: psicanálise; narrativa; transmissão; sujeito; real.

\section{Abstract}

PSYCHOANALYSIS AND MODERN NARRATIVE - THE QUESTION OF TRANSMISSION

Benjamin says, in The storyteller, that collective experience formerly supported by narrative gives place in modern times to the news information and the novel whose subject matter is the individual experience. It is the moment of the appearance of a narrative centered in the self or in the neurotic family romances discussed by Freud. But whereas in the romance and short tales aims to search for meaning that can support the vicissitudes of a self that finds

* Professora. Programa de Pós-graduação em Teoria Psicanalítica, UFRJ.

** Professora. Programa de Pós-graduação em Teoria Psicanalítica, UFRJ.

*** Mestre. Programa de Pós-graduação em Teoria Psicanalítica, UFRJ. 
no support a shared life. The psychoanalysis instead, the lack of immediate meaning of cultural life gives birth to a new praxis that accounts for a subject which does not match the individual self. The analyst's operation on history does not enlighten the meaning of things but on the contrary, it isolates the truth of the subject of the unconscious, thus founding the dimension of the real. Psychoanalytical transmission finds in this a different point of anchorage. Despite being set up in the same field as the modern forms of narrative, it makes for a field supported only by fragments and traces.

Keywords: psychoanalysis; narrative; transmission; real; subject.

Num escrito de 1933, Benjamin descreve como os combatentes da guerra de 1914-18 tinham voltado silenciosos dos campos de batalha, "mais pobres em experiências comunicáveis" ([1933] 1996: 115). Uma geração que ainda fora à escola em bondes puxados a cavalo viu-se de repente sem referências e confrontada a um novo campo de forças esmagadoras, cujas correntes explosivas depuseram as referências simbólicas que até então organizavam o mundo e produziram uma nova forma de miséria. Uma miséria que não era fruto apenas da corrosão dos meios pela inflação, nem da degradação do corpo pela fome e sim do progresso e desenvolvimento da técnica.

Tal miséria, sobreposta ao homem, distingue a "nova barbárie" de que fala Benjamin ([1933] 1996: 115). Barbárie positiva, pois nos obriga a começar de novo e partir de pouco, mas ainda assim barbárie, pois prenuncia o momento em que a ciência não vem apenas instrumentalizar a cultura, mas a sobrepuja - tomando seu lugar na ordenação do laço social.

Poucos anos mais tarde, em $O$ narrador, Benjamin ([1936] 1996) evoca a perda da experiência compartilhada (Erfahrung). Situa essa perda em sua relação com o declínio da narrativa, da arte de contar, que acompanhava e garantia a continuidade da experiência comum que se transmitia de pai para filho. É importante observar, entretanto, que esta tese não implica, para Benjamin, nenhuma nostalgia. Recusando decididamente qualquer concepção teleológica da história, o autor afasta-se da visão progressista da marcha humana e visa justamente às possibilidades de ruptura, de desvio da inércia imposta por esta marcha.

É neste contexto que ele se interessa pela questão da mudança na estrutura da experiência na modernidade e faz desta mudança o tema central de sua obra. Ao refletir sobre o declínio da experiência e da narrativa, distingue as condições de possibilidade do advento do sujeito histórico para tentar localizar seu lugar novo na transmissão.

Segundo o artigo de 1936, a narrativa valorizava a palavra do pai que, ao ser escutada pelo filho, dava ensejo à transmissão da tradição e da experiência. Assim, 
não se tratava apenas de passar conteúdos, mas de estabelecer uma cadeia que marcava lugares. Isto é, uma continuidade que não se dava tanto num eixo vertical da geração antiga para a mais nova, mas no plano horizontal, já que ocorria pela posição ocupada pelo filho frente à palavra do pai, para o qual a experiência seria transmitida e compartilhada.

O filho que ouvia a palavra do pai “incorporava as coisas narradas em sua experiência” (Benjamin, [1936] 1996: 201), e diríamos que ele tinha interesse em conservar o que lhe era narrado. A narrativa, então, não consistia numa explicação sobre determinado tema, mas concernia, antes, à assimilação do que era ouvido às próprias experiências daquele que ouvia; tratando do que só seria passado "de boca em boca”, (Benjamin, [1936] 1996: 198), de um a um. Com a modernidade, mostra Benjamin, o "dom de ouvir" desaparece, assim como não encontramos mais a "comunidade dos ouvintes" (Benjamin, [1936] 1996: 205).

Nessa cadeia de transmissão surge, portanto, uma inflexão ou uma interrupção, uma vez que a narrativa do pai não é mais ouvida, o que evoca ainda a experiência empobrecida pela "guerra das trincheiras": aquela em que "as forças impessoais e todo-poderosas da técnica", como ressalta Gagnebin (2004: 59), substituem as lutas que atravessam e se dão no corpo e com o corpo. Benjamin relaciona o declínio da narrativa ao fato de que, ao voltar para casa, os homens não podiam referir-se aos seus atos durante a guerra.

Não há o que contar e, mais importante, não há o que ouvir de uma guerra de metralhadoras e bombardeios aéreos. Estima-se que 35\% dos homens morreram nas trincheiras, enquanto aguardavam o momento do ataque ao inimigo, por não suportarem as condições de higiene, alimentação e convívio, lançando-se em direção ao campo do inimigo para serem logo metralhados; ou, então, se automutilavam para poderem se evadir dali. Essa condição exemplar, mencionada inúmeras vezes por Benjamin para dar conta do declínio da narrativa, vem se acrescentar à substituição das ocupações artesanais pelo fazer técnico, que avança rapidamente e serve de obstáculo a um ofício que se realiza na esfera do coletivo.

Gagnebin $(2004,2006)$ chama atenção, ainda, para o que denomina a "problemática do desaparecimento dos rastros" (Gagnebin, 2004: 58), ou do apagamento dos rastros que acompanha o declínio da narrativa. Problemática crucial, se consideramos que é com os rastros que se forja uma tradição. Os rastros são restos, pontos que caem do que é narrado, a partir dos quais se constitui a tradição apoiando-se nos fragmentos do que é contado. Uma vez mais não se trata de uma transmissão linear, da comunicação de conteúdos, mas de uma operação que vai se fazer em torno desse ponto que resta (ponto que não se completa na direção esperada), ponto que é apenas vestígio (Lo Bianco \& Araujo, 2007). 
No conto evocado por Benjamin ([1933] 1996), em que o pai moribundo indica aos filhos que há um campo que contém enterrado nele um tesouro - sucedendo que os filhos cavam e mexem na terra sem encontrar o tesouro, ao passo que a terra se torna fértil e produz a melhor colheita -, observa-se que a herança é uma operação realizada pelos filhos a partir de um ponto residual, não positivo, transmitido pelo pai.

É a partir desse ponto ínfimo e resistente à significação, que, no entanto, é conservado, resguardado e respeitado pelo filho, para além do seu próprio saber, que este se insere na cadeia de transmissão e faz seguir a tradição. Assim, o declínio da narrativa corresponde a um ponto da tradição que se rompe, que se esgarça e cria obstáculo à transmissão, constituindo deste modo um lugar - Freud ([1900] 1996: 321) diria "uma outra cena" - em que a experiência passa a ser valorizada pelo que ela guarda de singular, de idiossincrático e privado. Não estamos mais no terreno da Erfahrung, da experiência que como matéria de transmissão é sempre compartilhável e transmissível, e sim da Erlebnis, a "vivência" - "experiência interior" (Gagnebin, 2006: 59) que toma o lugar da experiência na cultura e remete ao vivido por cada um.

É este o momento em que a narrativa será substituída pela comunicação, pela informação jornalística, plausível e verificável. Momento a partir do qual se pode falar de "número de mortos" em lugar de falar de uma batalha em particular, com seus pequenos e grandes heróis, seus pequenos e grandes feitos. Como dirá mais tarde Chico Buarque, "a dor da gente não sai no jornal".

Benjamin ([1936] 1996) reconhece aí o surgimento do romance clássico, que toma a vida do personagem central para se interrogar sobre o seu sentido ou sobre o sem-sentido de sua experiência individual. Não se trata mais do que se ouve, mas do que se lê na esfera do impresso. $\mathrm{O}$ romance é a narrativa do eu, história de um indivíduo isolado, ao contrário daquela do narrador, que falava exemplarmente de suas experiências. Mesmo o Bildungsroman, que ainda tematiza o ensinamento dado ao jovem, evoca um personagem perplexo diante do mundo.

Com a modernidade, portanto, a narrativa passa a ser centrada no eu. Nesta passagem, o fio narrativo que tecia a trama da experiência compartilhada fica reduzido a uma função ilustrativa. E, importa frisar, dá lugar ao que Freud ([1909] 1995: 213) tão bem caracterizou como o "romance familiar dos neuróticos".

Freud ([1909] 1995: 217) reconhece que o "progresso da sociedade descansa, todo ele, nessa oposição entre as gerações dos pais e dos filhos”. O neurótico é aquele que "fracassa na tarefa" (Freud, [1909] 1995: 207) de tomar o seu lugar nessa oposição. O que era dado na transmissão anteriormente, ou seja, que um 
filho ouvisse a palavra do pai (e se situasse por relação a ela), torna-se uma questão a ser resolvida, podemos dizer, por cada um.

Freud observa, ainda, que a pequena criança não sabe mais que lugar ocupar na cadeia familiar. Há como que uma rede de intrigas que a faz se perder na inveja do pai, na incerteza de seu lugar frente ao casal parental, nos ciúmes dos irmãos... $\mathrm{O}$ romance em questão terá que ser construído individualmente, e é nessa construção que cada um poderá fazer o seu lugar. $\mathrm{O}$ romance do neurótico, Freud chega a dizer, "serve para retificar a sua vida" (Freud, [1909] 1995: 218).

Ora, esta nova relação com a palavra, decorrente da queda em derrisão da sabedoria tradicional e franqueada pelo desenvolvimento da ciência - "a mais emancipada que jamais existiu”, segundo Benjamin ([1936] 1996: 169) -, é a própria condição - ineliminável - do sujeito moderno. Rearticular a função constitutiva da narrativa no campo do sujeito não significa, portanto, promover um resgate - impossível e doravante inútil - de sua feição tradicional, mas, antes, implica uma tarefa incessante e fragmentária. A tarefa de fazer falar um passado imemorial que, apesar de não se manifestar mais como experiência, não deixa de se fazer ouvir.

É nesse ponto que podemos situar a invenção da análise como forma de dar lugar não a um resgate como tal do passado, mas ao sujeito que, ejetado da História, "sofre de reminiscências". Não encontrando o seu lugar já indicado (como seria na experiência compartilhada), trata-se para o neurótico de construir o seu lugar. No romance ou no conto, como vimos, isso se realiza pela busca incessante de sentido que suporta as vicissitudes das experiências de um eu que não encontra mais amparo na experiência comum. Com a análise, por outro lado, frente ao que se coloca como fracasso em ocupar ou em investir um lugar, inaugura-se uma práxis que concerne ao sujeito e não mais ao eu individual.

O interessante é que esta práxis - a psicanálise - restitui de certa forma algumas características da narrativa tradicional. Não apenas porque a análise se centra sobre uma narrativa oral (Meschonnic, 2007; Castro \& Lo Bianco, no prelo), mas, sobretudo, porque esta fala não se ordena exclusivamente pelo sentido positivo e, assim como a narrativa antiga, não constitui um discurso explicativo. Por outro lado, se a psicanálise conserva algumas características da narrativa, ela não restaura simplesmente a narrativa como considerada anteriormente, até porque suas condiçôes de possibilidade não existem mais. $\mathrm{O}$ que importa justamente é como, dadas as novas condições, a psicanálise se demarca do romance e da informação que surgem no mesmo tempo de declínio da narrativa, tal como considerada por Benjamin.

Voltando ao texto de Freud sobre os romances familiares (Freud, [1909] 1996), vale lembrar uma breve menção feita aos traços sobre os quais o sujeito se apoia para narrar a sua história. Na verdade, essa mesma ideia é mantida por 
Freud durante toda a sua obra. Trata-se sempre do que ele mais tarde vai chamar de "fósseis de referência" (Freud, [1939] 1996: 38), aos quais se remetem as construções feitas na narrativa de uma análise.

É sobre os traços que restaram da lembrança dos pais de sua infância que o neurótico criará o seu romance sobre os pais enaltecidos.

Lacan ([1953] 1998) localiza, precisamente nesses vestígios, um lugar de fenda no saber por onde a verdade do sujeito emerge e é resgatada. Eles aparecem na fala, e dão lugar às operações da história que são realizadas a partir desses vestígios $^{1}$. Apoiando-se neles é que será possível ao sujeito criar uma ordem histórica ou reordenar a sua história - que ao mesmo tempo toma "as contingências passadas" e as faz determinar "as necessidades por vir" (Lacan, [1953] 1998: 257). O autor refere-se a um corte que, ao mesmo tempo, faz emergir a verdade do sujeito e funda o real que terá estado aí desde sempre. O real que comparece, por exemplo, com a chamada "cena real" que reordena a história clínica no caso do "Homem dos lobos" (Freud, [1917] 1996: 93). Real que, desde que essa história mostrou portar a verdade do sujeito, terá servido (só depois) como ponto de ancoragem (ver também Lo Bianco, 2002).

A descoberta radical e sem precedentes desta "estranha temporalidade" (Lacan, [1964] 1985: 30), ligada à estrutura da narrativa do sujeito em análise, é inaugural e constitutiva do ato de Freud de invenção da psicanálise. Podemos ver as implicações disso na sustentação decidida de algumas posições de Freud com relação ao tempo e ao lugar da história na experiência psicanalítica. Em particular na insistência, que Lacan ([1964] 1985: 37-39) denomina "a certeza de Freud", que o leva a recorrer até mesmo a noções como as de "verdade histórica" e história filogenética (cf. Freud, [1939] 1996), pois "o que quer que seja, é preciso chegar lá" (Lacan, [1964] 1985: 37).

Quando consideramos esta insistência - que está na origem, por exemplo, da concepção freudiana da tarefa analítica como a de trazer à luz o "núcleo de verdade histórica" (Freud, [1939] 1996: 92) das formaçôes do inconsciente -, compreendese o que aqui nomeamos traços e vestígios que determinam a ligação inextrincável da narrativa analítica ao real, que ela mesma funda ao se constituir.

Eis aí uma condição em tudo diferente do romance clássico e da informação em cuja forma a comunicação é hegemônica. A injunção ética que a psicanálise dirige ao sujeito sob a forma da regra fundamental e única da prática analítica - a associação livre - visa, justamente, relançar o sujeito na via de outra articulação simbólica. Trata-se ainda de narrativa, mas uma narrativa cujo real não se constitui a partir da experiência compartilhável e, sim, em torno da instância que emerge com a ciência moderna e que Lacan ([1957] 1998) nomeia letra. Ou seja, "a estrutura essencialmente localizada do significante” (Lacan, [1957] 1998: 505). 
A partir da ciência, o real não se dá mais como campo da experiência produzida pelo significante, mas sim como o que se encontra fixado por pequenas letras intercambiáveis, definidas exclusivamente a partir da ordem de suas comutações. Essa substituição da dimensão significante da linguagem pela dimensão da letra, implicada na formalização que dá origem à ciência, acaba por dissolver a soldagem entre o significante e o sentido que era articulada através da narrativa pelas diversas culturas, com inúmeros efeitos.

A dimensão significante da linguagem, por suportar a ação operatória da diferença (a diferença irredutível que a linguística reconhece como "pura diferença" de que é feito cada significante), convoca o sujeito. Um significante sozinho não significa nada e gera, somente no enlace a outro significante, uma significação sem permanência, nem consistência fixa. Uma significação que se passará, necessariamente, "entre" dois significantes, produzindo o sujeito como efeito desta articulação. Já a dimensão da letra, ao contrário, constituída por elementos que valem por sua identidade algébrica e esvaziados de toda significação intrínseca, prescinde inteiramente do sujeito e, por isso mesmo, pode isolar o real. Assim, no mesmo golpe em que o real da queda dos corpos, por exemplo, é fixado numa lei ( $\mathrm{f}=\mathrm{ma})$, o sujeito é expulso - Lacan (1965-1966: lição de 01/06/66) diz "forcluído": há um ganho de saber decerto, mas o sujeito não é mais chamado a dar sentido a esse saber.

Por outro lado é justamente a operação da ciência sobre o significante - operação de esvaziamento, até o ponto de sua redução à letra - que produz o significante, tal como Freud vai encontrá-lo funcionando no campo do sujeito, o significante "livre" do significado. O significante, não significando nada em si mesmo, pode constituir, por isso mesmo, o discurso do outro - 1 . na forma das imagens que compõem o rébus do sonho; 2 . ou na configuração do sintoma como formação de compromisso que se articula a partir do duplo sentido; 3. ou, ainda, das lembranças (encobridoras ou não) - do mesmo modo que suporta a marcha inexorável da ciência.

A partir do significante produzido na operação da ciência, emerge o sujeito desnaturado que Descartes isolou como cogito. O sujeito absolutamente heterogêneo aos termos em que é formulado (Lacan, 1967-1968). Sujeito que retorna nas narrativas em análise, mas que advém sempre em corte, em descontinuidade com a esfera do saber ${ }^{2}$.

Este sujeito esvaziado, depurado de toda característica intrínseca que lhe permitiria definir-se ou identificar-se, aparece a Freud na queixa histérica. Esvaziado, reduzido pela operação da ciência a não existir mais que como ponto (é o cogito), que só tem acesso à certeza como ato, fora do saber. $\mathrm{O}$ sujeito, órfão da rede simbólica que a experiência compartilhada garantia, só pode reaparecer no real 
dos atos e dos sintomas; apenso à contingência de uma atualização inantecipável e não inteiramente simbolizável. É a este sujeito, que perde sua inserção na cadeia de transmissão com o advento da ciência e subsiste apenas como ponto de fuga, que se refere o discurso psicanalítico. O mesmo sujeito, que a ciência tenta reintroduzir no cálculo como variável, Freud situa no campo do desejo inconsciente a partir do texto produzido em análise, um texto composto de restos. Texto de uma narrativa fragmentária, cuja significação não encerra o sujeito, mas, sim, suscita uma abertura para sua emergência real na enunciação.

Assim, para a psicanálise, o real do sujeito é constituído, na tessitura da narrativa, como resto ineliminável que suscita a reiteração da articulação simbólica (Costa-Moura, 2005). Freud pode reconhecer, nas narrativas em análise, este efeito real de sujeito que a linguagem produz e que ela mesma não é capaz de conter na forma de uma relação unívoca. É neste ponto, radicalmente esquivo, que se ancora a cadeia de transmissão articulada pela psicanálise. Uma transmissão que se dá se, e quando, um apagamento específico do sujeito acontece não mais em benefício pura e simplesmente do ganho de saber proporcionado pela operação da letra, mas da veiculação daquilo que a letra porta de presença e da palavra do Outro - o que implica todo o trajeto de uma análise.

\section{REFERÊNCIAS}

Benjamin, W. (1935-1936/1996). A obra de arte na era de sua reprodutibilidade técnica. In: Benjamin, W. Obras escolhidas. Magia e técnica, arte e política. São Paulo: Editora Brasiliense.

Benjamin, W. (1936/1996). O narrador. Em Benjamin, W. Obras escolhidas. Magia e técnica, arte e política. São Paulo: Editora Brasiliense.

Benjamin, W. (1953/1996). Experiência e pobreza. In: Benjamin, W. Obras escolhidas. Magia e técnica, arte e política. São Paulo: Editora Brasiliense.

Castro, J. de M. \& Lo Bianco, A. C. (no prelo). A disciplina de leitura: ritmo e oralidade na voz do texto. Psicologia \& Sociedade.

Costa-Moura, F. (2005). Adolescência: efeitos da ciência no campo do sujeito. Revista Psicologia Clínica, 17(2), 87-98.

Freud, S. (1900/1996). La interpretación de los sueños. Obras completas, v. IV. Buenos Aires: Amorrortu.

Freud, S. (1909/1996). La novela familiar de los neuroticos. Obras completas, v. IX. Buenos Aires: Amorrortu. 
Freud, S. (1917/1996). De la historia de una neurosis infantil. Obras completas, v. XVII. Buenos Aires: Amorrortu.

Freud, S. (1939/1996). El hombre Moisés y la religión monoteísta. Obras completas, v. XXIII. Buenos Aires: Amorrortu.

Gagnebin, J. M. (2004). História e narração em Walter Benjamin. São Paulo: Perspectiva. Gagnebin, J. M. (2006). Lembrar escrever esquecer. São Paulo: Editora 34.

Lacan, J. (1953/1998). Função e campo da fala e da linguagem em psicanálise. Escritos. Rio de Janeiro: Jorge Zahar.

Lacan, J. (1957/1998). A instância da letra no inconsciente ou a razão desde Freud. Escritos. Rio de Janeiro: Jorge Zahar.

Lacan, J. (1964/1985). O seminário, livro 11: os quatro conceitos fundamentais da psicanálise. Rio de Janeiro: Jorge Zahar.

Lacan, J. (1965-1966). L'objet de la psychanalyse. Seminário inédito.

Lacan, J. (1967-1968). L’acte psychanalytique. Seminário inédito.

Lo Bianco, A. C. \& Araujo, A. V. (2007). Fragmentos: a construção do histórico em Freud. Revista do Departamento de Psicologia, 19, 359-368.

Lo Bianco, A. C. (2002). A cena real construída no Homem dos lobos. Estilos da Clínica (USP), 12, 146-155.

Meschonnic, H. (2007). La poética como crítica del sentido. Buenos Aires: Mármol Izquierdo Editores.

\section{Notas}

1 Tais operaçôes também se dão a partir de monumentos (como o corpo), de documentos (como as lembranças infantis) ou de evoluçôes semânticas (como o vocabulário e o estilo do sujeito). (Cf. Lacan, [1953] 1998: 260-261).

2 Lacan faz dois extensos comentários sobre o Cogito cartesiano - um no seminário de 1964 e outro no seminário inédito L'acte psychanalytique (1967-1968). Em ambos ressalta o que o sujeito cartesiano comporta de corte, de descontinuidade com a atividade do pensamento, de onde supostamente este sujeito emergiria. No seminário de 1967-1968 (lição de 17 de janeiro de 1968), chega a afirmar que a existência (vale dizer, o real do sujeito) só pode ser auferida pelo ato de Descartes de impor uma suspensão a todo saber. Não haveria, portanto, nenhuma imediaticidade do "je suis" ao "je pense", mas antes a emergência do sujeito como resto que "cai", que sobra, que excede a articulação do pensamento impondo sua presença real.

Recebido em 15 de junho de 2009 Aceito para publicação em 10 de fevereiro de 2010 